\title{
SUBJECTS OR PARTICIPANTS? \\ THE DEVELOPMENT OF ETHICAL PRINCIPLES IN RESEARCH INVOLVING HUMANS IN THE UNITED STATES
}

\author{
Kathryn Obenchain, Bob Ives ${ }^{1}$ \\ University of Nevada, Reno
}

For anyone who has taken or taught a psychology course in the last 30 years, lectures and notes about infamous research studies in which people, put in novel situations, displayed surprising, and sometimes frightening behaviors were part of those courses. These studies were typically discussed in light of the goals of the studies, as well as the surprising results. The results less often discussed were the U.S. government's 1974 investigation of these experiments and the establishment of a commission to identify, in part, basic ethical principles in research involving humans.

Two of the studies which drove the creation of the commission were the Milgram Shock Study (Milgram, 1963) of 1961 and the Zimbardo Prison Study (Haney, Banks \& Zimbardo, 1973; Zimbardo, 2007) of 1973. The Milgram Study, conducted by Yale University professor, Stanley Milgram, occurred over the course of one year. Milgram, long interested in European conformity research, wanted to more explicitly explore obedience behaviors related to sound-based stimuli. In sum, participants were told that they were to administer electric shock to individuals located in another room, whenever those individuals gave an incorrect answer. The participants were told that the shock should increase in intensity with each incorrect answer given by the individual in the other room. Of course, no shocks were actually given as the individuals in the other room were study confederates, actors who were told to respond with cries of pain and distress when administered a simulated shock. A surprisingly large percentage of participants administered the (simulated) maximum and potentially lethal shock to individuals. The second study, named after Stanford professor, Dr. Phillip Zimbardo, occurred in the summer of 1971 (see www.prisonexp.org for detailed information). Focused on the effects of prison

\footnotetext{
${ }^{1}$ Adresa de corespondență: kmo@unr.edu, rives@unr.edu, University of Nevada, Reno, Mail Stop 299, NV 89557, USA
}

life on individuals, Zimbardo and his associates built a simulated prison and recruited males to participate in the experiment. The males, all of whom were told that this was an experiment and that they were free to leave at any time, were randomly assigned a role as either a prisoner or guard. The planned two-week experiment ended after six days because of the extreme and disturbing psychological changes observed in the participants.

\section{The Belmont Report}

Although separated by more than 10 years, the publicity around the disturbing psychological effects on the participants of these two studies provided the impetus for the United States government to address ethical issues for research involving humans. Convened in 1974, the National Commission for the Protection of Human Subjects of Biomedical and Behavioral Research (1979) released what is referred to as The Belmont Report. The contents of this report continue to be used to guide researchers in the treatment of human participants in research. We, the authors of this article, as employees of a federally-funded university, are legally bound by these guidelines, whether we conduct research in the United States or another nation. We are also required to ensure that any research collaborators we have also follow this principles. The two major parts of the Belmont Report are the basic ethical principles of research, followed by the application of those principles to research studies.

\section{Basic Ethical Principles and Application}

Respect for persons. The central foci of this category are that, (1) potential research participants should be treated as autonomous individuals, capable of making wise decisions about their participation in research, when they are provided with adequate information and are not coerced, and (2) those individuals with limited autonomy, perhaps a young child, a prisoner, or someone with a cognitive impairment, may need extra protection when participating in research. These individuals 
may even be excluded from research because of their limited autonomy.

Beneficence. Simply defined, beneficence means to treat with kindness, not just because it is required, but because it is the right thing to do, and that definition is the basis for inclusion in the Belmont Report. Similar to the Hippocratic Oath taken by medical professions, the goal of doing no harm is central. No person should be asked to participate in research in which there is an expectation of harm to an individual, nor should the conduct of research be harmful to society at large. From another perspective, even if the benefits of the research to society are large, that is not an adequate rationale for harming an individual. Reflect back on the Milgram and Zimbardo studies. The research community and society benefit from what was learned from those studies. However, most believe that those benefits did not outweigh the harm done to the participants' psyches. Recognizing that all research will include some risk, beneficence also requires that every research study proposal address the riskbenefit ratio. Given that, research is approved in which there is some risk, if the benefits outweigh the risk. It is nearly impossible to gain approval for research in which the risk is greater than any benefit.

Justice. The third ethical principle that the Belmont Report addresses is justice. This category addresses fairness in participating in and benefiting from research. No individual or group should consistently benefit from or bear the burden of the risks of participation in research. Participation in, benefiting from, and exposing oneself to the risks of research should be fairly shared. For example, prisoners should not always be asked to participate in research, just because they may be an easily accessible and controlled group. That is an unfair burden to this group of individuals. Nor should another group consistently benefit from research, because they are easily accessible.

\section{Application of the Ethnical Principles}

The application of these ethical principles is the second major portion of the Belmont Report. While researchers are familiar with the ethical principles, the researchers are not the appropriate people to determine issues of respect, beneficence, and justice for their own studies. Dr. Zimbardo became so engrossed in his prison study, he became a participant and had to be talked into ending the experiment. So, research institutions such as universities establish Institutional Review Boards (IRB) to review all planned research involving humans. At our university, we must submit our research plan to our university IRB, and they review and approve (or reject) our research plan. The review has one focus does the research conform to the ethical principles protecting humans involved in research stated above?

One important component of the IRB process designed to ensure respect for persons is informed consent. Typically, this involves a written document given to, and reviewed with, potential participants. The document contains a variety of information, including: notification that participation is voluntary, what the study is about, what the participants will experience and how much time they must commit, risks and benefits of participation, contact information for the researchers, and how the confidentiality of the participants will be protected. The confidentiality and privacy of the participants is crucial in many research studies. There must be structures in place to make sure that the only people who can disclose participation, are the participants themselves. Further, privacy may be protected by using pseudonyms. Consider a research study that explores employees' beliefs and practices about stealing from their employer (e.g., office supplies, equipment, money). The results of this study could provide valuable information for corporations in protecting their assets. However, if the identities of participants were released to their employers or future employers, the employees' jobs might be at risk. The informed consent process and accompanying documents are not a contract between researchers and participants. Rather, it is an explanation of the research and a promise by the researchers to abide by that explanation.

\section{Conclusion}

The title of this article considers the possibility of a perceptual difference between viewing an individual as a research subject or a research participant. The Belmont Report views the individual as a willing participant in research, not someone subjected to research. It is important to note that the Belmont Report is culturally bound. It is heavily influenced by the culture and traditions of the dominant culture in the United States, which has a distinct focus on the protection of the rights of the individual. This is not to say that the 
greater good is not important, but rather, that a society that does not prioritize and protect basic human rights, does not aspire to a greater good.

\section{References}

Haney, C., Banks, C., Zimbardo, P. (1973). Interpersonal dynamics in a simulated prison. Internanational Jurnal of Criminology and Penology, 1, 69-97.
Milgram, S. (1963). Behavioral study of disobedience. Journal of Abnormal and Social Psychology, 67, 371-378.

National Commission for the Protection of Human Subjects of Biomedical and Behavioral Research. (1979). The Belmont report. Retrieved October 23, 2007, from http://www.hhs.gov/ohrp/humansubject/gui dance/belmont.htm

Zimbardo, P. (2007). The Lucifer effect: Understanding how good people turn evil. New York: Random House.

\title{
D\&D Consultants, Bucureşti \\ www.ddconsultants.ro
}

\author{
Instrumente psihometrice publicate de D\&D Consultants / TestCentral \\ - CPI: California Psychological Inventory $(462,434,260)$ \\ - NPQ: Nonverbal Personality Questionnaire \\ - FFNPQ: Five-Factor Nonverbal Personality Questionnaire \\ - SWS: Survey of Work Styles \\ - STAXI-2: State-Trait Anger Expression Inventory \\ - FPI: Freiburger Personlichkeitsinventar (Formele G si R) \\ - LSI: Learning Styles Inventory \\ - MLQ: Multifactor Leadershp Questionnaire (Forma 5X) \\ - STAI: State-Trait Anxiety Inventory \\ - STAIC: State-Trait Anxiety Inventory for Children \\ - JVIS: Jackson Vocational Interest Survey \\ Instrumente psihometrice în curs de apariție \\ - AMI: Achievement Motivation Inventory \\ - ASSET: A Shortened Stress Evaluation Tool
}

